\title{
PELATIHAN PEMBUATAN PUPUK ORGANIK CAIR (POC) SEBAGAI ALTERNATIF PENGGANTI AB MIX PADA PERANGKAT HIDROPONIK DI SMA KEBANGSAAN PONDOK AREN
}

\author{
Oleh: \\ Yuni Astuti ${ }^{*}$, Maryanti Setyaningsih², Suci Lestari3, Devi anugrah ${ }^{4}$ \\ Pendidikan Biologi FKIP UHAMKA \\ yuni.astuti@uhamka.ac.id
}

\begin{abstract}
Abstrak
Kegiatan pengabdian kepada masyarakat yang dilakukan oleh tim dari UHAMKA yang dilaksanakan pada tanggal 26 Januari dan 9 Februari 2019 di SMA Kebangsaan Pondok Aren, Tangerang Selatan ini telah memberikan sumbangan yang sangat berarti bagi warga sekolah tersebut. SMA Kebangsaan merupakan sekolah menengah yang terdapat di Kota Tangerang Selatan yang dijadikan mitra. Sekolah ini dinilai cukup strategis sebagai sasaran kegiatan pengabdian ini karena letaknya dekat dengan pasar tradisional Ceger, dimana bahan dasar pembuatan POC berupa limbah sayur dan buah sangat melimpah. SMA Kebangsaan mempunyai instalasi hidroponik yang digunakan untuk pengaplikasian POC sebagai nutrisi alternatif pengganti $A B-M I X$. Tujuan pengabdian ini untuk memanfaatkan limbah pasar di sekitar lingkungan sekolah sebagai nutrisi alternatif pegganti $A B$ MIX pada perangkat hidroponik. Metode pelaksanaan kegiatan berupa pelatihan yang terdiri dari penyuluhan tentang konsep POC sebagai nutrisi alternatif penanaman secara hidroponik, praktik pembuatan POC, dan latihan pengoperasian alat penunjang pembuatan $\mathrm{POC}$, seperti $\mathrm{pH}$ meter, TDS/EC meter, dan timbangan digital. Hasil kegiatan pengabdian ini adalah 98\% peserta dapat mengolah limbah sayur dan buah menjadi POC. Kegiatan pelatihan ini memberikan kemudahan kepada guru dalam menerapkan proses pembuatan POC sebagai media pembelajaran sehingga dapat meningkatkan motivasi guru sebesar $85 \%$. Kendala yang dihadapi adalah aroma asam yang menyengat dari POC yang mengganggu kenyamanan warga sekolah dan adanya belatung (larva lalat) pada POC yang membuat sebagian siswa merasa tidak nyaman untuk menggunakan POC pada instalasi hidroponik di sekolah.
\end{abstract}

Kata Kunci: Pupuk Organik Cair (POC), Sayur dan Buah, Nutrisi Hidroponik

\begin{abstract}
The community dedication activities carried out by the team from UHAMKA, which was held on January 26 and February 9, 2019, held at Pondok Aren National High School, South Tangerang, have contributed significantly to the residents of the school. Kebangsaan High School is a secondary school located in South Tangerang City which is made a partner. This school is considered quite strategic as the target of this service activity because it is located close to the Ceger traditional market, the basic ingredients of making $P O C$ in the form of vegetable and fruit waste are very abundant. Senior High School Kebangsaan has a hydroponic installation that is used for the application of POC as an alternative nutrient substitute for $A B$ MIX. The purpose of this dedication is to utilize market waste around the school environment as an alternative nutrient to replace $A B M I X$ on hydroponic devices. The method of implementing the activity was in the form of training which consisted of counseling about the concept of $P O C$ as an alternative nutrition for hydroponics, the practice of making POC, and training in the operation of POC manufacturing tools, such as $\mathrm{pH}$ meters, TDS / EC meters, and digital scales. The result of this service is that $98 \%$ participants can process vegetable and fruit waste into POC. This training activity makes it easy for teachers to apply the process of making POC as a learning medium so that it can increase teacher motivation by $85 \%$. The obstacle faced is the stinging sour aroma of POC which disturbs the comfort of the school citizens and the presence of maggots (fly larvae) in POC which make some students feel disgusted for an application to hydroponic installations.
\end{abstract}

Keywords: Liquid Organic Fertilizer, Vegetable and Fruit, Hydroponic nutrition

PENDAHULUAN

Fermentasi adalah salah satu konten yang dipelajari oleh mahasiswa Prodi Pendidikan Biologi. Fermentasi terkait dengan proses katabolisme yang dapat mengolah bahan organik menjadi unsur karbon yang sederhana. Aplikasi dari kajian fermentasi adalah pembuatan Pupuk Organik Cair (POC). POC dapat dibuat menggunakan 
bahan dasar sisa limbah dapur yaitu sayur dan buah yang telah busuk. Hal senada dijelaskan oleh (Siboro, Surya, \& Herlina, 2013) bahwa pupuk organik cair dapat dihasilkan dengan mengolah limbah sayuran Berdasarkan hasil penelitian kolaborasi dosen dan mahasiswa Prodi Pendidikan Biologi tentang "Pemanfaatan Pupuk Organik Cair (POC) Limbah Sayur Dan Buah Dari Pasar Tradisional Kramat Jati Sebagai Alternatif Nutrisi Pada Perangkat Hidroponik" (Setyaningsih \& Astuti, 2018) diperoleh kesimpulan bahwa POC limbah sayur dan buah yang digunakan bersamaan dengan $A B$ MIX berpengaruh terhadap pertumbuhan tanaman. Hasil penelitian tersebut menjadi landasan untuk mengadakan kegiatan pelatihan pembuatan POC sebagai wadah dosen dalam melaksanakan tanggung jawab pengabdian kepada masyarakat. Namun, penggunaan $\mathrm{POC}$ sebagai nutrisi tanaman hidroponik tidak bisa digunakan secara mandiri karena unsur haranya kurang sehingga perlu adanya penambahan AB-MIX. Temuan tersebut diungkapkan oleh (Omaranda, Setyono, \& Adimihardja, 2016) bahwa penggunaan pupuk organik cair harus disertai dengan penggunaan pupuk $A B$ Mix demi mencapai hasil yang optimal dengan komposisi $A B$ Mix $50 \%$ atau lebih.

Pengetahuan dalam pembuatan POC sangat dibutuhkan bagi guru maupun siswa di sekolah. Dengan membuat POC, guru akan sangat terbantu dalam memberi penjelasan mengenai proses fermentasi kepada siswa. Selain itu, dengan memanfaatkan instalasi hidroponik di sekolah, siswa akan lebih tertarik untuk mengelola hidroponik tersebut melalui penggunaan POC hasil karya siswa dalam penanaman sayuran.

SMA Kebangsaan merupakan salah satu sekolah menengah yang terdapat di Kota Tangerang Selatan. Sekolah ini dinilai cukup strategis sebagai sasaran dalam kegiatan pengabdian ini karena terletak dekat dengan pasar tradisional Ceger, dimana bahan dasar pembuatan POC sangat melimpah. SMA ini juga memiliki instalasi hidroponik yang kurang difungsikan dengan baik. Aliran air nutrisi yang tidak merata menyebabkan setiap lok tanaman mendapatkan nutrisi yang berbeda. Pipa saluran nutrisi berlumut karena terlalu lama tidak dipakai. Kurangnya pengetahuan dan pengalaman guru dan siswa melatarbelakangi permasalahan mitra. Berdasarkan uraian tersebut, maka perlu dilakukan kegiatan pelatihan pembuatan POC sebagai salah satu upaya pemanfaatan limbah pasar di sekitar lingkungan sekolah untuk dijadikan pupuk alternatif pengganti $A B$ MIX pada perangkat hidroponik.

\section{METODE}

Pengabdian ini dilakukan pada tanggal 26 Januari dan 9 Februari 2019 di SMA Kebangsaan Pondok Aren, Tangerang Selatan.

Metode yang digunakan untuk menyelesaikan permasalahan mitra adalah Pelatihan yang meliputi: a) kegiatan penyuluhan tentang materi Hidroponik dan Pupuk Organik Cair (POC) disertai dengan demonstrasi pembuatan POC berbahan limbah sayur dan buah, b) pelatihan dalam pengoperasian timbangan, $\mathrm{pH}$ meter dan TDS/EC meter yang dioperasikan secara digital sebagai alat untuk menguji kualitas POC.

Pembuatan POC terdiri dari: a) penimbangan limbah sayur dan buah; b) pencacahan bahan limbah sayur dan buah menggunakan pisau selanjutnya dihaluaskan menggunakan blender; c) perendaman limbah sayur dan buah dalam larutan EM4 dan larutan gula selama 2-4 minggu, selanjutnya dilakukan penyaringan; d) pengujian kualitas larutan $\mathrm{POC}$ menggunakan $\mathrm{pH}$ meter dan TDS/EC meter; e) penggunaan produk POC pada instalasi hidroponik untuk penanaman tanaman bayam.

Data yang diperoleh dalam pengabdian ini berupa data kualitas POC dan tanggapan peserta terhadap pelatihan pembuatan POC berbahan dasar limbah sayur dan buah. Data kualitas POC diperoleh dengan pengukuran $\mathrm{pH}$ dan TDS larutan POC, sedangkan data tanggapan peserta diperoleh melalui penyebaran angket yang bersifat terbuka. Data $\mathrm{pH}$ dan TDS dibandingkan dengan nilai standar ph dan TDS untuk penanaman tanaman bayam. Hasil angket dihitung persentase respon pesertanya.

\section{HASIL DAN PEMBAHASAN}

Pelatihan pembuatan Pupuk Organik Cair (POC) di SMA Kebangsaan terdiri dari dua sesi yaitu sesi pemaparan materi "Hidroponik dan POC" disertai demonstrasi pembuatan POC dan pelatihan dalam pengoperasian timbangan, $\mathrm{pH}$ meter dan TDS/EC meter. Pada sesi pemaparan materi, Bapak Devi Anugrah, M.Pd. menjelaskan tentang definisi, jenis, dan manfaat teknik bercocoktanam pada instalasi hidroponik dan langkah 
pembuatan POC. Pada saat narasumber menjelaskan materi, para peserta terlihat antusias dengan adanya banyak pertanyaan yang diajukan terkait dengan materi hidroponik dan POC. Narasumber juga memperlihatkan contoh-contoh hidroponik sederhana. Kegiatan penyajian materi dapat dilihat pada Gambar 1.

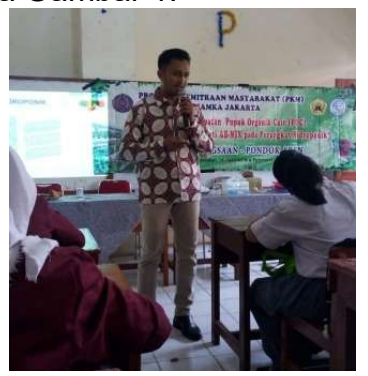

Gambar 1. Pemaparan Materi dan Praktik Pembuatan POC

Peserta dibagi menjadi lima kelompok, masing-msing beranggotakan 5-6 orang. Peserta mulai proses penimbangan sayur dan buah yang dibawa sebelumnya menggunakan timbangan digital. Kegiatan dilanjutkan dengan pencacahan dan penghalusan limbah sayur dan buah, seperti terlihat pada Gambar 2.

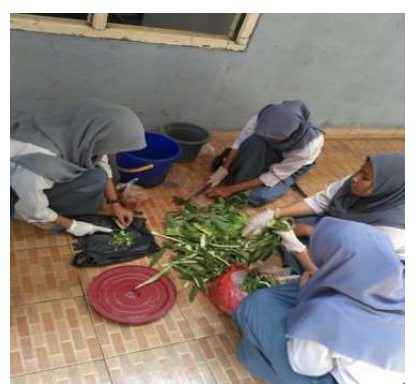

Gambar 2. Peserta Melakukan Pencacahan Limbah Sayur dan Buah

Tujuan pencacahan dan penghalusan bahan dasar adalah untuk memperkecil ukuran sayur dan buah sehingga proses dekomposisi sayur dan buah menjadi POC berlangsung lebih cepat. Seperti yang dijelaskan oleh Rao dan Subba (1994) dalam (Astuti, 2000) bahwa faktor yang mempengaruhi laju dekomposisi bahan organik yaitu jenis dan ukuran partikel bahan organik, jenis dan jumlah mikroorganisme, ketersediaan $\mathrm{C}, \mathrm{N}, \mathrm{P}, \mathrm{K}$, kelembaban tanah, temperatur, $\mathrm{PH}$, dan aerasi. ukuran bahan sayur dan buah. Setelah halus, limbah sayur dan buah dimasukkan ke dalam ember. Ember tersebut digunakan sebagai wadah fermentasi limbah sayur dan buah.
Selanjutnya ditambahkan $10 \mathrm{ml}$ larutan Em4 untuk setiap $\mathrm{kg}$ limbah, seperti terlihat pada Gambar 3. Pemberian larutan EM4 dapat mempercepat proses fermentasi dan dekomposisi limbah sayur dan buah karena mengandung mikroorganisme yang berperan sebagai dekomposer. Untuk makanan mikroorganisme, maka perlu penambahan larutan gula secukupnya. Tutup wadah fermentasi lalu tunggu prosesnya selama kurang lebih 14 hari.

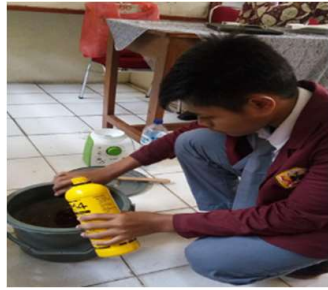

Gambar 3. Penambahan Larutan EM4 ke dalam Wadah Berisi Larutan Limbah Sayur dan Buah

Tutup ember diberi klep udara dengan cara membuat lubang sesuai dengan diameter selang, ujung selang yang lain dimasukkan ke dalam botol air mineral yang telah diisi air. Hal tersebut bertujuan untuk menjaga kelambaban POC dan aliran udara di dalam wadah sehingga suhu di dalam wadah stabil.

Kegiatan pelatihan dilanjutkan setelah 14 hari perendaman limbah sayur dan buah yaitu pada tanggal 9 Februari 2019. Pada tahap ini dilakukan pengecekan kualitas produk POC yang telah dibuat 14 hari yang lalu oleh peserta pelatihan. Hasil POC dapat dilihat pada Gambar 4.

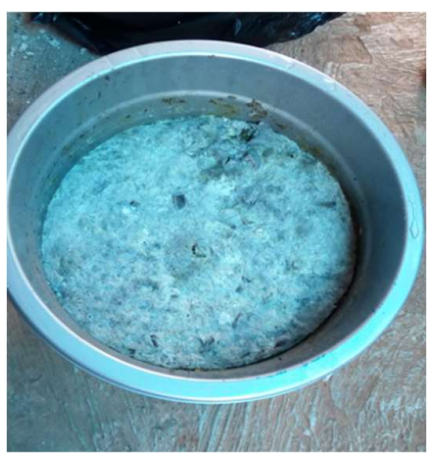

Gambar 4. Hasil POC berbahan dasar sayur dan buah

Produk POC yang dibuat diletakkan dalam dua wadah. Hasilnya di semua wadah terdapat jamur pada permukaan POC. Hal tersebut wajar karena salah satu mikroorganisme yang terkandung di dalam 
EM4 adalah jamur actinomycetes dan jamur peragian. Menurut Sutanto (2000) dalam (Kusuma, 2012) menerangkan bahwa Mikroorganisme Efektif (EM4) merupakan kultur campuran berbagai jenis mikroorganisme yang bermanfaat (bakteri fotosintetik, bakteri asam laktat, ragi, actinomycetes, dan jamur peragian). Jamur lebih menyukai $\mathrm{Ph}$ asam dengan rentang $\mathrm{Ph}$ pertumbuhan dari 5-8 (Zaman \& Sutrisno, 2007), Selain jamur, ditemukan juga larva lalat pada salah satu wadah. Adanya larva lalat juga adalah hal yang wajar karena bahan dasar pembuatan POC berupa limbah sayur dan buah yang sebagian telah busuk sehingga mungkin telah mengandung telur lalat. Adanya jamur dan larva lalat bukanlah indikator kegagalan pembuatan POC. Indikator keberhasilan pembuatan POC antara lain aroma POC yang harum seperti fermentesi tape, $\mathrm{pH}$ asam, tidak berbau busuk, dan cairannya lebih encer.

Selanjutnya dilakukan penyaringan untuk memisahkan air dengan ampasnya menggunakan saringan, seperti terlihat pada Gambar 5. Peserta dan fasilitator perlu menggunakan masker dan sarung tangan dalam proses penyaringan karena bau fermentasi agak menyengat karena berasal dari bahan dasar sayur. Berdasarkan hasil penelitian (Setyaningsih \& Astuti, 2018), memang limbah sayur menghasilkan aroma POC yang lebih menyengat.

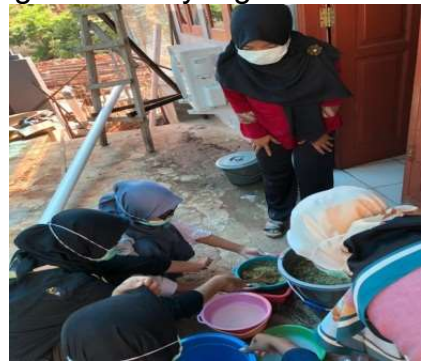

Gambar 5. Proses Penyaringan POC

POC yang telah disaring, diukur kualitasnya menggunakan $\mathrm{pH}$ meter dan TDS meter. Penggunaan $\mathrm{pH}$ meter bertujuan untuk mengukur derajat keasaman POC sedangkan TDS meter digunakan untuk mengukur partikel padatan yang terlarut dalam POC. Hal ini sangat penting karena POC yang dihasilkan akan digunakan sebagai nutrisi pada perangkat hidroponik. Proses pengukuran $\mathrm{pH}$ dan TDS dapat dilihat pada Gambar 6.

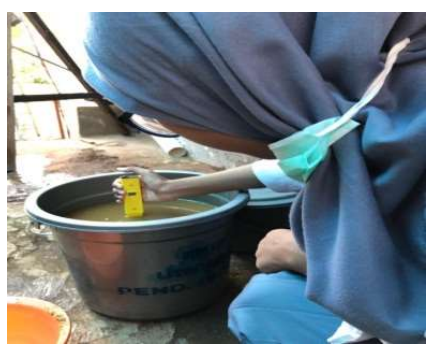

Gambar 6. Pengukuran $\mathrm{pH}$ pada Larutan POC Menggunakan $\mathrm{pH}$ meter Digital

Pupuk Organik Cair (POC) yang dihasilkan dalam kegiatan pelatihan ini memiliki aroma seperti hasil fermentasi pada umumnya yaitu berbau asam menyengat, dengan nilai $\mathrm{pH}$ mencapai 5 dengan TDS sebesar 1400 ppm. Hasil ini sudah sesuai dengan standar mutu pupuk organik cair berdasarkan hasil pembahasan para pakar lingkup Puslitbangtanak, Direktorat Pupuk dan Pestisida, IPB jurusan tanah, Deperindag, serta Asosiasi Pengusaha Pupuk dan Pengguna pada tahun 2006 (Suriadikarta dan Setyorini, 2013) dalam (Handayani, Yunus, \& Susilowati, 2015) yang menyatakan bahwa $\mathrm{Ph}$ pada larutan POC 4-8. Untuk penggunaannya, POC perlu dalam disimpan beberapa hari agar $\mathrm{pH}$ mendekati normal (67). Selain itu, POC yang hendak digunakan harus diencerkan dulu agar nilai TDS lebih kecil sehingga dapat digunakan sebagai nutrisi pada penanaman bayam di instalasi hidroponik.

Peserta "Pelatihan Pembuatan Pupuk Organik Cair (POC) Sebagai Alternatif Pengganti AB MIX Pada Perangkat Hidroponik Di SMA Kebangsaan Pondok Aren" dapat dilihat pada Gambar 7.

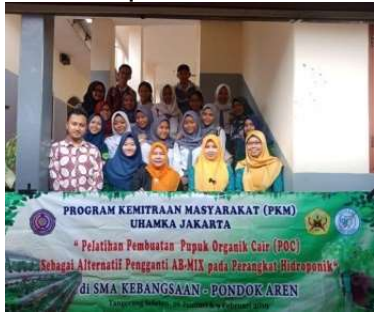

Gambar 7. Peserta Pelatihan Pembuatan POC

Keunggulan pembuatan POC berbahan dasar limbah sayur dan buah dapat mengurangi sampah sayur dan buah dari pasar di dekat sekolah. Selain itu, pihak sekolah dapat mengurangi biaya operasional penggunaan instalasi hidroponik dengan memanfaatkan POC. Kelemahannya adalah aroma POC yang berbau agak menyengat 
sehingga pihak sekolah perlu menyediakan lokasi pembutan POC agar tidak mengganggu proses pembelajaran di sekolah mitra. Selain itu, adanya larva lalat (belatung) yang membuat sebagian orang merasa jijik.

Tingkat kesulitan pelaksanaan kegiatan ini terletak pada aroma POC yang dihasilkan sangat berbau menyengat terutama bila POC berbahan dasar lebih banyak sayur. Hal ini menyebabkan peserta perlu memikirkan lokasi penyaringan larutan POC agar aromanya tidak mengganggu warga sekolah.

Peserta pelatihan memberikan tanggapan yang positif terhadap pelaksanaan kegiatan pembuatan POC. Tanggapan peserta secara lengkap tertera pada Tabel 1.

Berdasarkan hasil angket tersebut diperoleh

Tabel 1. Tanggapan Peserta "Pelatihan Pembuatan Pupuk Organik Cair (POC) Sebagai Alternatif Pengganti AB MIX Pada Perangkat Hidroponik Di SMA Kebangsaan Pondok Aren"

\begin{tabular}{clcc}
\hline \multirow{2}{*}{ No. } & \multicolumn{1}{c}{ Aspek yang dinilai } & \multicolumn{2}{c}{ Skor Kepentingan (\%) } \\
\cline { 2 - 4 } & \multicolumn{2}{c}{ Ya } & Tidak \\
\hline 1. & Kejelasan penyajian materi Hidroponik dan POC & 98 & 2 \\
\hline 2. & Kesesuaian materi dengan tujuan pelatihan & 100 & 0 \\
\hline 3. & $\begin{array}{l}\text { Kesempatan peserta untuk aktif bertanya dan } \\
\text { berpendapat }\end{array}$ & 90 & 10 \\
\hline 4. & $\begin{array}{l}\text { Kemudahan penerapan pembuatan POC sebagai media } \\
\text { pembelajaran Biologi }\end{array}$ & 85 & 15 \\
\hline 5. & $\begin{array}{l}\text { Kecukupan dan ketersediaan alat dan bahan penunjang } \\
\text { pelatihan }\end{array}$ & 80 & 20 \\
\hline 6. & Metode pelatihan yang diterapkan & 95 & 5 \\
\hline
\end{tabular}

Tabel 1 menunjukkan bahwa 98\% peserta menyatakan materi disajikan secara jelas sehingga peserta dapat mengolah limbah sayur dan buah menjadi POC dengan baik. Kegiatan pelatihan ini memberikan kemudahan kepada guru dalam menerapkan proses pembuatan POC sebagai media pembelajaran pada materi Fermentasi. Hal tersebut berdampak pada meningkatnya motivasi guru sebesar $85 \%$ dalam mengaplikasikan proses pembuatan POC sebagai media pembelajaran.

\section{SIMPULAN DAN SARAN}

\section{Simpulan}

Simpulan yang dapat dirumuskan setelah pelaksanaan pengabdian yang berjudul "Pelatihan Pembuatan Pupuk Organik Cair (POC) Sebagai Alternatif Pengganti AB MIX Pada Perangkat Hidroponik Di SMA Kebangsaan Pondok Aren" adalah adanya peningkatan kemampuan siswa dan guru dalam proses pembuatan POC berbahan dasar limbah sayur dan buah sebesar $98 \%$. Proses tersebut memudahkan siswa dalam memahami konsep fermentasi sebagai salah satu proses dekomposisi sampah menjadi pupuk. Motivasi guru meningkat $85 \%$ dalam mengaplikasikan proses pembuatan POC di kelas. Selain itu, alat pembuatan POC yang dihibahkan ke sekolah dapat dimanfaatkan sebagai media untuk menunjang pembelajaran Biologi, terutama konsep Fermentasi.

\section{Saran}

Beberapa saran yang disampaikan untuk peningkatan kualitas kegiatan pengabdian ini antara lain:

1. Perlu adanya pendampingan pembuatan POC dan aplikasinya pada perangkat hidroponik secara berkesinambungan agar pihak mitra dapat terus konsisten dalam memanfaatkan ilmu yang sudah diperoleh.

2. Menjalin kerjasama dan menjaga silaturahmi yang baik dengan pihak mitra.

3. Sebaiknya perbanyak limbah buah, terutama tomat dan nanas, yang digunakan sebagai bahan dasar pembuatan POC agar aroma POC lebih harum.

\section{DAFTAR PUSTAKA}

Astuti, A. (2000). Retrieved 2019, from repository umy:

http://repository.umy.ac.id/handle/12345 6789/7145

Handayani, S. H., Yunus, A., \& Susilowati, A. (2015, April). Uji Kualitas Pupuk 
Organik Cair dari Berbagai Macam Mikroorganisme Lokal (MOL). ELVIVO, 3(1), 54-60.

Kusuma, M. E. (2012). Pengaruh Berbagai Jenis Pupuk Kandang terhadap Kualitas Bokashi. Jurnal Ilmu Hewani Tropika, 2(1), 41-46.

Omaranda, T., Setyono, S., \& Adimihardja, S. A. (2016, April). Efektivitas Pencampuran Pupuk Organik Cair dalam Nutrisi Hidroponik pada Pertumbuhan dan Produksi Tanaman Selada (Lactuca sativa L.). Jurnal Agronida, 2(1), 37-46.

Setyaningsih, M., \& Astuti, Y. (2018).

Pemanfaatan Pupuk Organik Cair (POC)

Limbah Sayur Dan Buah Dari Pasar
Tradisional Kramat Jati Sebagai Alternatif Nutrisi Pada Perangkat Hidroponik. Jakarta: Lemlitbang UHAMKA.

Siboro, E. S., Surya, E., \& Herlina, N. (2013). Pembuatan Pupuk Organik Cair dan Biogas dari Campuran Limbah Sayuran. Jurnal Teknik Kimia USU, 2(3).

Zaman, B., \& Sutrisno, E. (2007). Studi Pengaruh Pencampuran Sampah Domestik, Sekam Padi, dan Ampas Tebu dengan Metode Mac Donald terhadap Kematangan Kompos. Jurnal Presipitasi, 2(1), 1-7. 